УДК 65

DOI: $10.14451 / 1.187 .82$

\title{
ПЛАНИРОВАНИЕ ЭФФЕКТИВНОЙ РАБОТЫ ТЭЦ
}

\section{(c) 2020 Сухарева Евгения Викторовна}

кандидат экономических наук, доцент кафедры Экономики в энергетике и промышленности Национальный исследовательский университет «МЭИ», Россия, Москва

E-mail: sukharevayevv@mpei.ru

В статье представлен обзор технических и экономических критериев эффективности работы ТЭЦ. Рассмотрено влияние конкурентных энергорынков на деятельность ТЭЦ. Описана взаимосвязь ТЭЦ и генерирующей компании. Сформированы сценарии планирования деятельности ТЭЦ.

Ключевые слова: эффективность ТЭЦ, планирование работы ТЭЦ, критерии эффективности, конкурентные энергорынки, функционирование ТЭЦ.

Согласно стандарту ГОСТ Р ИСО 9000-2015 Системы менеджмента качества: Эффективность (efficiency) - это соотношение между достигнутым результатом и использованными ресурсами [1].

Основное требование, которое предъявляется к показателям работы ТЭЦ, состоит в том, чтобы они позволяли оценить экономическую эффективность как работы ТЭЦ в целом, так и производства каждого вида энергии в отдельности.

Обычно расчеты показателей эффективности ведутся для ТЭЦ в целом и отдельно для каждого теплофикационного энергоблока, энергетического котла, теплофикационного турбоагрегата и пикового котла. Такие расчеты осуществляются для различных временных периодов: года, квартала, месяца, суток.

Основными показателями эффективности текущей деятельности ТЭЦ являются расход топлива и коэффициент полезного действия [2].

Расход топлива в энергетическом котле для производства электроэнергии:

$$
B_{\ni}=\frac{Q_{\ni}}{Q_{H}^{p} \cdot \eta_{m p} \cdot \eta_{\kappa}}
$$

где $Q_{\ni}-$ количество теплоты, затраченной турбиной на производство электроэнергии, $Q_{H}^{p}-$ низшая теплота сгорания топлива; $\eta_{m p}-$ КПД транспортировки теплоты, который учитывает потери теплоты в окружающую среду на участке паропровода от энергетического котла до регулирующих клапанов турбины; $\eta_{\kappa}-$ КПД котла (брутто).

КПД турбоустановки по производству электроэнергии:

$$
\eta_{m y}^{\ni}=\frac{N_{\ni}}{Q_{\ni}}
$$

где $N_{\ni}$ - электрическая мощность тубоустановки.

Удельный расход топлива на единицу выработанной электроэнергии:

$$
b_{\ni}=\frac{B_{\ni}}{N_{\ni}}=\frac{1}{Q_{H}^{p} \cdot \eta_{\sigma л}^{\ni}}
$$

где $\eta_{б л}^{\ni}=\eta_{m y}^{\ni} \cdot \eta_{m p} \cdot \eta_{\kappa}-$ КПД теплофикационного энергоблока по производству электроэнергии.

КПД теплофикационной турбоустановки по отпуску тепловой энергии:

$$
\eta_{m y}^{m}=\frac{Q_{m . o m}}{Q_{m}}
$$

где $Q_{m . o m}-$ количество теплоты, полученной внешним потребителем из регулируемых отборов; $Q_{m}-$ количество теплоты, отпущенной с паром регулируемых отборов.

КПД энергоблока по отпуску тепловой энергии:

$$
\eta_{\text {бл }}^{m}=\eta_{m y}^{m} \cdot \eta_{m p} \cdot \eta_{\kappa}
$$

Расход топлива на производство теплоты, переданной внешнему потребителю:

$$
B_{m}=\frac{Q_{m . o m}}{Q_{H}^{p} \cdot \eta_{\sigma л}^{m}}
$$

Удельный расход топлива, затраченного на производство единицы теплоты, переданной внешнему потребителю:

$$
b_{m}=\frac{B_{m}}{Q_{m . o m}}
$$


Общий расход топлива составляет:

$$
B=B_{\ni}+B_{m}
$$

Энергетическая эффективность теплофикации оценивается по экономии топлива, получаемой при удовлетворении от ТЭЦ заданного энергопотребления, по сравнению с расходом топлива при раздельной выработке электрической энергии на конденсационных электрических станциях и теплоты в котельных [3]:

$$
\Delta B=B_{P}-B_{T}
$$

где $B_{P}$ - расход топлива при раздельной выработке электрической энергии и теплоты; $B_{T}-$ то же при теплофикации.

Другим возможным методом оценки эффективности теплофикации является расчет коэффициента использования теплоты топлива $\eta_{И}$. Коэффициент использования теплоты топлива (полный КПД ТЭЦ) представляет собой отношение тепловых эквивалентов, отпущенных от ТЭЦ теплоты и электрической энергии к тепловому эквиваленту сожженного топлива:

$$
\eta_{u}=\frac{Q+\ni}{B \cdot Q_{H}^{p}}
$$

где $Q$ - количество отпущенной теплоты;

Э- количество отпущенной электроэнергии.

До создания конкуренции на рынках энергии эффективность работы теплоэлектроцентрали оценивали с помощью показателей удельного расхода топлива на выработку тепловой и электрической энергии. В период плановой экономики и энергетики задачу планирования производственно-хозяйственной деятельности станции решали с позиции минимизации общих затрат, минимизации затрат на топливо или минимума расхода топлива [4].

\section{Затраты $\rightarrow$ min}

Поэтому, основной задачей повышения эффективности работы ТЭЦ было распределение нагрузки по генерирующим агрегатам так, чтобы расход топлива, а значит и издержки на топливо, или общие затраты на производство были минимальными.

Для планирования работы ТЭЦ в такой по- становке используется метод относительных приростов расхода условного топлива. Характеристики относительных приростов рассчитываются для каждого генерирующего агрегата станции. Наиболее эффективным является режим, когда вначале загружаются агрегаты с минимальными величинами относительных приростов условного топлива. Достоинством данного метода является его простота исчисления. В связи с этим, он довольно часто применялся до настоящего времени [5].

На сегодняшний день необходимо принимать в учет условия функционирования конкурентных рынков: ОРЭМ и вводимого сейчас нового рынка тепловой энергии. Современная постановка задачи планирования работы ТЭЦ на конкурентных рынках не проста в вычислении благодаря сложному виду целевой функции; довольно большое число варьируемых параметров для агрегатов станции; огромное число ограничений, накладываемых на значения управляемых параметров. Одним из критериев для планирования работы ТЭЦ на конкурентных рынках является прибыль, которую необходимо увеличить до максимума на некотором интервале времени, называемом периодом планирования [6]. Современная задача планирования производственно-хозяйственной деятельности ТЭЦ ставится следующим образом:

\section{Прибыль $=($ Выручка - Затраты $) \rightarrow \max$}

В зависимости от продолжительности временного периода, для которого требуется максимизировать прибыль, а соответственно, и повысить эффективность деятельности станции, выделяется четыре типа задач планирования:

1) Долгосрочная - продолжительностью от одного года до нескольких лет, используется при планировании консервации существующих мощностей и времени ввода в эксплуатацию новых агрегатов.

2) Среднесрочная - сроком от месяца до одного года, используется для планирования ремонтных работ генерирующего оборудования, а также для формирования заявок на конкурентный отбор мощности (КОМ).

3) Краткосрочная - длительностью от суток до месяца, применяется для подготовки заявок для процедуры ВСВГО, ценовых заявок для PCB, а также оперативных заявок на балансиру- 
ющий рынок.

4) Оперативная - для одного или нескольких часов, требуется для уменьшения издержек на топливо при выполнении известных графиков нагрузок, диктуемых потребителями тепловой и электрической энергии.

Задача повышения эффективности решается для $\mathrm{t}=1,2,3 \ldots, \mathrm{T}-$ дискретных равноотстоящих моментов времени, где Т - период планирования. Разность двух соседних моментов является константой и равна $\Delta \mathrm{t}$. Так как расчеты на ОРЭМ осуществляются на каждый час суток, то задачу повышения эффективности работы ТЭЦ в условиях обоих конкурентных рынков решается с шагом в 1 час $(\Delta t=1$ час). Отметки времени $t$ будут соответствовать началу часа.

Внедрение конкуренции на рынках энергии требует от электростанций перестройки системы планирования деятельности для теплофикационной электростанции, включающей формирование гибкой ценовой политики с учетом факторов рынка, улучшение экономических результатов деятельности станции за счет более эффективного и рационального использования генерирующих мощностей.

Совершенствование планирования производственно-хозяйственной деятельности для теплоэлектроцентрали имеет некоторую сложность, так как они работают одновременно на двух рынках: электрической и тепловой энергии. В связи с этим, финансово-экономические показатели деятельности ТЭЦ будут обуславливаться как режимами производства электрической энергии, так и выработкой тепловой, поэтому необходимо планирование производственнохозяйственной деятельности станции при комбинированной работе по электрическим и тепловым графикам. Помимо этого, нужно учесть то обстоятельство, что рынок тепловой энергии носит местный характер, а рынок электрической энергии, чаще всего,- региональный. Так при потере конкурентоспособности на рынке тепловой энергии неизбежно вытеснение станции и рынка электрической энергии [7]. В связи с этим, необходим комплексный подход к учету особенностей обоих рынков одновременно.

Для конкурентных рынков энергии прибыль является одним из главных показателей деятельности любого предприятия. Это один из собственных источников финансирования для текущего и будущего состояния организации, фактор, способствующий увеличению стоимости компании, показатель кредитоспособности и конкурентоспособности, инструмент расширения бизнеса. Необходимо поддерживать уровень прибыльности, так как это критерий эффективного функционирования компании для рыночной экономики. Энергокомпании не могут увеличивать свою прибыль за счет выхода на рынок новых видов продукции, поэтому в энергетике одним из главных факторов рыночного успеха является минимизация издержек. Снижение удельных расходов на единицу при поддержании требуемых качеств и параметров позволяет электростанции реализовывать энергию по сниженным по сравнению с конкурентами ценам, а значит, и увеличить объемы продаж, получив в результате максимальный объем прибыли. Объем реализации продукции, а соответственно, и прибыль, напрямую зависят от ценового фактора. В условиях конкурентного рынка цена формируется под воздействием спроса и предложения. Таким образом, равновесная цена рынка зависит не от конкретного участника рынка, а является результатом совместного поведения всех продавцов и покупателей.

На основе анализа рынков тепловой и электрической энергии построена факторная модель валовой прибыли ТЭЦ, представленная на рисунке 1.

Кроме того, теплоэлектроцентраль непосредственно не является отдельным предприятием, а входит в какую-либо генерирующую компанию (ОГК или ТГК). Необходимо разграничить сферы планирования, присущие ТЭЦ и генерирующей компании (ГК). Под работу отдела планирования ТЭЦ попадают все технические параметры: такие как выбор состава и режимов работы оборудования, расчет размера вредных выбросов в окружающую среду, а также некоторые экономические, например, текущие затраты станции. В свою очередь, ГК занимается формирование бухгалтерской отчетности, составлением учетной политики, занимается уплатой налогов, в т.ч. платы за негативное воздействие на окружающую среду, планирует цены для формирования ценовых заявок. Работа всех отделов ТЭЦ и ГК взаимосвязана, а значит каждое подразделение должно учитывать наиболее эффективные варианты для всех участников.

Исходя из проведенного анализа можно выделить следующие предпосылки для формиро- 


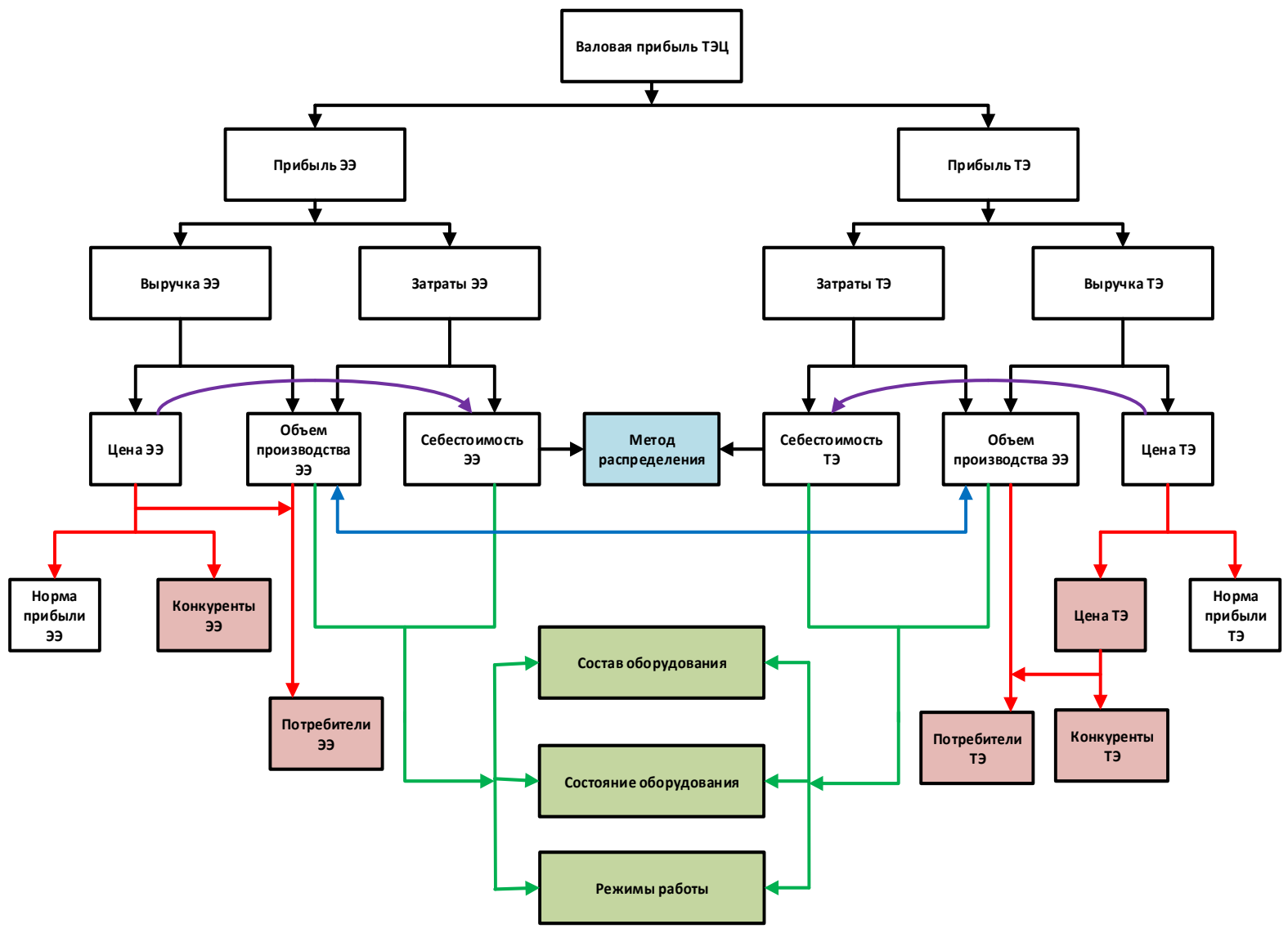

Puc. 1. Факторная модель валовой прибыли ТЭЦ с учетом факторов рынка

вания подходок к повышению эффективности деятельности ТЭЦ:

1) необходим комплексный подход, который будет учитывать:

- экономические и технические особенности энергетического предприятия;

- многокритериальность задачи планирования;

- повышение эффективности как ГК в целом, так и отдельной ТЭЦ.

2) в качестве критериев эффективности можно использовать предложенные ранее минимум текущих затрат или максимум чистой прибыли, но с учетом корректировок современной экономической и рыночной ситуаций:

- не только минимум суммарных текущих затрат, а минимум затрат, упитывающихся при прохождении процедуры ВСВГО (выбор состава включенного генерирующего оборудования);
- конкретизация максимума определённого вида прибыли в каждом конкретном случае.

Учитывая все вышесказанное, сформирована совокупность сценариев, определяющих условия функционирования ТЭЦ на конкурентных энергорынках в условиях долгосрочного и краткосрочного периодов, представленная на рисунке 2.

Долгосрочный период планирования предполагает:

1) строительство новой станции;

2) модернизацию существующей станции;

3) консервацию станции или блока.

В краткосрочном периоде при работе на действующей станции предусматриваются управление затратами ТЭЦ, формирование ценовой политики, управленческие решения по устранению различий бухгалтерского и налогового учета и двусторонней взаимосвязи ТЭЦ и ГК. 
Сценарии планирования деятельности ТЭц
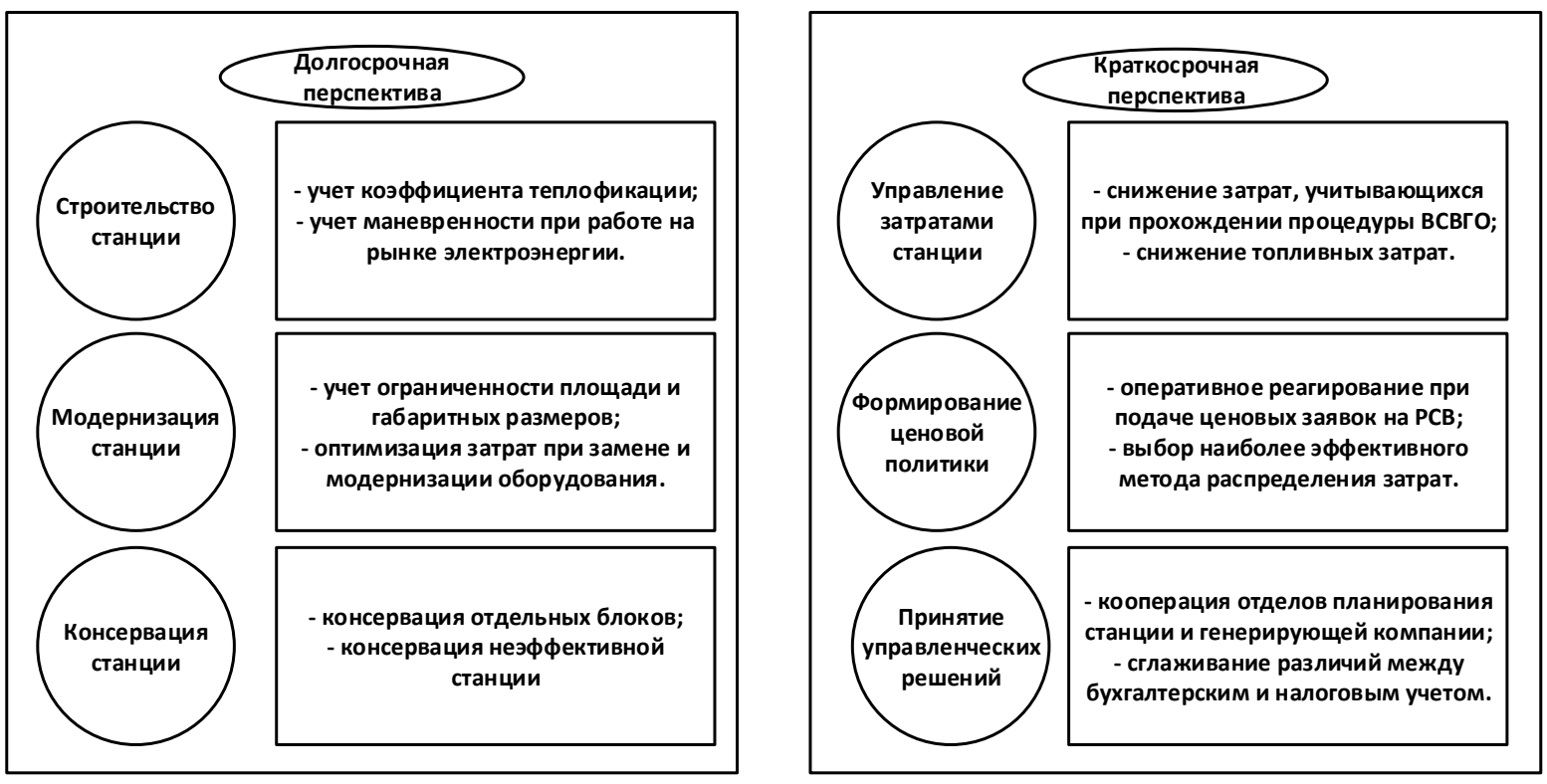

Puc. 2. Сценарии планирования деятельности ТЭЦ

\section{Библиографический список}

1. ГОСТ Р ИСО 9000-2015 Системы менеджмента качества

2. Буров, В.Д. Тепловые электрические станции: учебник для вузов. / В. Д. Буров, Е. В.Дорохов, Д. П. Елизаров, и др.; под ред. В. М. Лавыгина, А.С. Седлова, С.В.Цанева. - 3-е изд., стереот.- М.: Издательский дом МЭИ, 2009.- 466 с.

3. Соколов, Е.Я. Теплофикация и тепловые сети: Учебник для вузов.-7-е изд. Стереот / Е. Я. Соколов - М.: Издательство МЭИ, 2001.-472с.

4. Аракелян, Э. К. Методика многокритериальной оптимизации покрытия суточных графиков электрической нагрузки с учетом реальных динамических характеристик оборудования ТЭС/ Э. К. Аракелян, С. А. Минасян, Г. Э. Агабабян // Труды международной научной конференции, CONTROL-2005,- М.: Изд. МЭИ, 2005.

5. Сухарева, E.B. Совершенствование методики технико-экономического обоснования выбора основного энергетического оборудования для газотурбинной электростанции/ Е. В. Сухарева, Е. М. Лисин, И.И. Комаров, Г.Н. Курдюкова // Экономика и предпринимательство. - 2015. - № 8, часть 1.- С. 716-722.

6. Сухарева, E.B. Механизм планирования производственно-хозяйственной деятельности теплофикационной электростанции в условиях конкурентных энергорынков: дис. канд. экон. наук: 08.00.05 / Сухарева Евгения Викторовна.- Москва. - 2017.- 200 с.

7. Гительман, Л.Д. Энергетический бизнес: учебное пособие / Л.Д.Гительман, Б.Е.Ратников.- М.: Дело, 2006. -600 c. 